\title{
MANAGING RESEARCH OR MANAGING KNOWLEDGE? A DEVICE TOOL FOR QUALITY ASSURANCE
}

\author{
António Monteiro ${ }^{1,2}$, A. Jorge Morais ${ }^{3,4}$, Marlene Nunes ${ }^{1} \&$ Diana Dias ${ }^{1,5}$ \\ ${ }^{1}$ Universidade Europeia I Laureate International Universities (PORTUGAL) \\ ${ }^{2}$ Centro Interdisciplinar de Ciências Sociais - CICS.NOVA - FCSH/Universidade Nova \\ de Lisboa (PORTUGAL) \\ ${ }^{3}$ Universidade Aberta, Porto (PORTUGAL) \\ ${ }^{4}$ Laboratory of Artificial Intelligence and Decision Support, LIAAD-INESC TEC, Porto
}

(PORTUGAL)

${ }^{5}$ Center for Research on Higher Education Policies, CIPES (PORTUGAL)

\begin{abstract}
Research management promotes an integrated approach to identifying, capturing, evaluating, retrieving, and sharing all of a higher education institutions' research information assets. These assets may include databases, documents, policies and procedures. Conceptually linked, knowledge and research assume critical relevance as an essential tool to insuring Higher Education institutions quality. Institutions are challenged to develop robust (internal) quality assurance systems in which information about scientific production, research projects, staff curricula are considered as relevant indicators. This commitment with science and research is also visible by the opportunities promoted by institutions for the academic development of their staff. Accordingly, the assessment of research and science indicators becomes an essential step for the definition of research development programmes in HE institutions.

Based on this framework, it was developed an online questionnaire to be answered by academic staff, trying to assess some science and research indicators. Trying to measure the research potential of all faculty staff, this assessment tool is organized in distinctive four dimensions, namely researcher's (i) biographic data, (ii) scientific identification, scientific outputs (books, Books' chapters, scientific paper indexed and proceedings), (iii) research project with competitive funding and (iv) suggestions to improve research production. In what concerns to the application, all faculty staff members (teachers and researchers) were invited to contribute. The results were presented and discussed personally and collectively with all academic community. These results also provide relevant Key Performance Indicators, also known as KPIs or Key Success Indicators (KSIs), that could help managers and researchers gauge the effectiveness of various functions and processes important to achieving organizational goals. If scientific research is a strategic priority to higher education institutions, this kind of KPIs could be used to help academic managers to assess whether they or their faculty/research staff are on or off target towards those goals.
\end{abstract}

Keywords: Research, Quality, Technology, Science 


\section{INTRODUCTION}

In recent past, Higher Education in Portugal has experienced substantial changes, as an answer to Bologna challenges (1). One of this challenges is the promotion of quality assurance between European Higher Education systems, based on curricula comparability. Hence, assessment methodologies, scientific contents, and scientific measures need to be aligned, to allow a comparison between not only study programs, but also between Higher Education institutions (1). In line, the definition of a common "Framework for Qualification of European Higher Education" to be adopted by the European countries could be seen a clear example of this comparability and transparency request (2).

The university research mission is now perceived to be a primary engine of economic development and national policies therefore seek to strengthen academic research and doctoral education, while improving the channels linking university research and industrial innovation (3). The academic ideal is no longer the university as a bastion of knowledge and culture, but rather the 'entrepreneurial university' (4). The emphasis on university research as an engine of economic development has been stimulated by recent insights into the nature of technical innovation and the important role played in this process by university research and doctoral education (5). In the current climate of heightened accountability research assessment has become the most pervasive instrument used in many countries (3). Thus, quality assurance and assessment are critical as key indicator for design strategic policies. Collect data becomes very important in order to ensure that the records of research - sometimes referred to as the 'minutes of science' - provide an accurate record of what has been found. Universities and other research institutions have various measures in place to try to ensure that they recruit and retain staff who will produce high-quality research, confer prestige on the institution, and attract research funding. Assessments of track record to date - with particular emphasis on publications in high-status journals - play a critical part in recruitment and promotion decisions.

New technologies and services have already changed the ways in which assurance and assessment is done. New technologies are also facilitating the development of a wide range of sophisticated bibliometric and other measures that can provide useful evidence to support assurance and assessment systems. One of the key issues for the future will be how these new tools and techniques evolve alongside more traditional systems of assurance and assessment of the quality of research.

Whatever the changes, however, assurance and assessment systems will remain critical to the efficiency of the research development, helping to ensure that key decisions are taken properly and based on good evidence; and providing an essential underpinning for sustaining trust in the work that researchers undertake.

Thus, this research aims to validate the use of Google Forms as a tool for conducting data collection about the research key indicators, such as scientific production, research projects, faculty staff curricula at a Portuguese university. The research intends to explore a technological tool to o measure the research potential of all faculty staff. Results are presented and their discussion is developed to validate the usefulness and adequacy of the data collection instrument developed to the purposes of this study.

\section{THEORETICAL FRAMEWORK}

\subsection{Research as a crucial issue in the university mission}

Since Wilhelm von Humboldt work (1767-1835), considered the theorist of the Modern German University (6), also known as "University of Research", a long and systematic discussion has been 
happening around the University' role, not only in education, but also in the cultural and social context which it is inserted. With the evolution of education systems and policies, University, originally recognized as the home of knowledge, extends their role beyond the Institution itself. In the post-war period, many theorists use Humboldt to defend the new role of universities in society (7). For instance, since the 1970s onwards, the weak economic performance of the more developed societies led to a knowledge-based economy and, consequently, a greater emphasis on scientific and rigorous knowledge (8). Humboldt's legacy, according to some authors (6) (9), will have been one of the pillars for the Knowledge Society as we know it today, where teaching and research are closely linked (9). Although the research university model has been systematically questioned and rethought over the years, it has nowadays become an unavoidable approach (10), specially at the beginning of the 21 st century with the exponential increase of the knowledge transfer.

In a study carried out in 2015 in Italy, about the evaluation of educational institutions through the research they produce (6), the research role in universities is reinforced, noticing that "research competencies are useful for Professionals in a knowledge society, and because higher education is only able to deliver these competencies if their education is related to research. "(p.514). Besides the way the research quality was evaluated, their importance is recognized as undeniable in a context in which peer recognition is fundamental (10).

Thus, research management promotes an integrated approach to identifying, capturing, evaluating, retrieving, and sharing all of a higher education institutions' research information assets. These assets may include databases, documents, policies and procedures. Conceptually linked, knowledge and research assume critical relevance as an essential tool to insuring Higher Education institutions quality.

\subsection{Research as a crucial key indicator of institutional quality}

Institutions are challenged to develop robust (internal) quality assurance systems in which information about scientific production, research projects and staff curricula are considered as relevant indicators. This commitment with science and research is also visible by the opportunities promoted by institutions for the academic development of their staff. Accordingly, the assessment of research and science indicators becomes an essential step for the definition of research development programs in HE institutions.

The quality of research is crucial to the recognition of the institution and its placement in the international rankings. This quality assurance opens the doors to more students willing to apply for the institution and to more funding of the research itself. Research results increase knowledge, and knowledge transmission is one of the key missions of higher education institutions. Research Information Network (11) advocates that assurance and assessment regimes, tools and techniques will thus continue to evolve in response to not only the increases in the volume of research, but also the increased pressure on costs. The need to bear down on costs will continue to make pressure to find more streamlined systems and techniques. On the other hand, assurance and assessment of research activity increased competition between researchers. In fact, constraints on funding bring increased competition for research grants and contracts, falling success rates, more work for assurance and assessment systems, and more difficult decisions in determining which projects, researchers and institutions succeed in the competition. Similar pressures are evident as researchers compete for space in prestigious publications. New kinds of research outputs are also promoted by research quality assurance. Many assurance and assessment systems are built around outputs that are formally published in journals, monographs and conference proceedings. And data intensive research brings a new focus on data as an output in its own right. Assurance and assessment regimes will need to keep up with these new outputs and forms of communication. 


\subsection{Technology as a crucial tool to assess research and science key indicators}

As referred, HE institutions are confronted with the need of develop strong quality assurance systems to collect data about scientific production, research projects, staff curricula are considered as crucial to the Higher Education institutions quality assessment, making available research and science key indicators.

In fact, Technology plays an important role, with the creation of databases with indexed publications (Web of Science, Scopus, DBLP, etc.) allowing research information to be spread worldwide, which brings several advantages:

- Researchers have access to a large database of research papers and books, allowing them to deepen their knowledge and know what already exists in order to focus on developing new original and innovative research.

- Automatic computation and release of statistics about access to documents and citations, impact factors, h-index, etc., allows an easier way to check the relative importance of each work to the research community.

- Public access to publications and researchers' information increases confidence on the results of the research made and allows comparability among others, leaving less space to arbitrary judgement, and is a step towards distinguishing institutions that prefer quality to quantity.

With such a relevant information, higher education institutions may develop policies to support original and innovative research, encouraging their researchers to direct their efforts to publish in high impact factor journals and submit papers to relevant conferences.

Technology is also important to bring researchers together, enabling easier communication between researchers worldwide and the creation of wider networks from all different continents. In an international institution, this becomes even more relevant, allowing information exchange in order to level its institutions and creating minimum standard goals.

The evolution of computing, with the advent of distributed and parallel computing, and the creation of clusters that enabled massive parallel processing, it became possible to process large data in a lower amount of time, benefiting all the academic community and allowing them to experiment and analyse data that was very difficult to process. With the new technology of cloud computing it is even easier, because clusters may be anywhere instead of being physically at the institution. The evolution of data mining techniques and algorithms also permitted an easier way of analysing massive data, discovering hidden patterns that would not be easily found with classical statistical methods.

\section{METHODOLOGY}

\subsection{Procedure}

A newly established university in Portugal recognizes research as one of the fundamental vectors in its mission. It further recognizes that its research performance is of great importance for promoting the university's reputation abroad. In the scope of the vice rector for the investigation, a new team is in charge of evaluating the scientific potential of the faculty staff. In this sense, it is important to make a diagnosis of the research potential of the faculty staff, not only to function as a key indicator for the definition of a strategic policy in the field of research, but also to serve as a source of information for the quality department. In fact, research outputs are seen as strong 
indicators of institutional quality.

Thus, a multidisciplinary team was set up to respond to this objective. This team included the research vice-rector, a senior research support specialist, a technology specialist, and another specialist in library, archiving and documentation management. Together, enhancing the synergies of the different scientific approaches in which each one is specialized, it was tried to find a technological solution that would serve as a tool for collecting the necessary data to diagnose the research potential of the faculty staff of this newly constituted university. It was about defining what would be asked, in a conceptual basis (content of the questionnaires and expected results) and how it would be asked, in an operational basis (technological solution as a data collection tool).

\subsubsection{Conceptual concerns}

Following the logical steps to develop a good questionnaire advocated by Aaker, Kumar \& Day (12), the first concern of the research team was to plan what to measure. The survey aims were clarified and all the pretended outputs were meticulously explored. Using brainstorming with inputs from all research team, it was made an exploratory research of each one of the considered variables. After listing all the variables to be measured by the questionnaire, a confirmatory analysis was made of the adequacy of the questions to be asked with the results that were intended to be obtained. Thus, it was confirmed that all key indicators needed for the internal quality assurance system were in fact measured by the data collection tool.

After an exhaustive survey of all the key indicators needed, the conceptual approach was implemented in terms of formulating questions. At this time, it was discussed the degree of freedom of response to be given to respondents. According to each key indicator focused, it was chosen the question type more adequate: open ended with no classification, open ended with pre-coded classifications used to record the response or close ended or structured format with responses to be considered.

The next concern of the research team was the order and wording of questions and the layout of the questionnaire. It was attempted that the right questions were effectively asked and that the respondents not only understood the questions, but also knew the answers and were willing to give them. Other concerns have been taken into consideration, namely: opening questions (easy and non-threatening), flow (smooth and logical, avoiding jumps), broad to specific, critical questions (placed in the middle), appealing and interesting and order bias (the possibility that subsequent responses are influenced by preceding responses).

Then, a test was performed for omissions and ambiguity and all the detected problems were corrected. For this, two pre-tests were carried out: one after the omissions and ambiguities test and the other after the first error correction. Specific Questions were pretested in terms of meaning, task difficulty and interest and attention perceived by respondents. The overall questionnaire was also pretested to assess their flow, to skip patterns and their length suitability.

\subsubsection{Choice of the technological solution}

The choice of the technological solution took into account some aspects:

- It should fit all the goals of the questionnaire.

- It should automatize all the basic steps of a questionnaire, from the design of the form with the questions to the recording of the answers.

- It also should be, as far as possible, ready to use, so that we could use most of our time with the questionnaire itself rather than with the development of the solution.

Our choice was to use Google Forms with Google Drive. This service is one of the tools provided 
by Google, a well-known Internet search tool. With Google Forms, we can easily create a form, with several types of questions: text, multiple choice, ordering options, etc. This questionnaire is linked to multiple spreadsheets (Google Spreadsheet, another Google tool) that record the answers, according to our settings, and may also preserve the anonymity of the responder, if needed.

Both the form and the spreadsheet, are saved in Google Drive, which is a cloud file directory, making them accessible everywhere through an Internet connection. Since Google Drive also provides synchronization with the local drives for most of the operating system (Windows, Linux, OS, Android, etc.), we may also work offline if there is no Internet connection. Google Spreadsheet also has the ability to export these results into other popular formats (Microsoft Excel Spreadsheet, Comma Separated Values, etc.). Other advantages include a easy-to-use interface, with no programming skills needed, and the fact that it is free software.

By creating a Google Form, it is possible to develop all the research work, including the definition of the questions, answer alternative types, form design, and even the data tables with the answers for analysis, online and in real time. It is also possible to share it with the faculty staff (a link to the questionnaire can be created and sent by email) so that they can answer it online and submit it. All the answers are automatically recorded on Google spreadsheets. By exporting this spreadsheet to a Comma-Separated Values (CSV) file, we may then work the answers, for instance, in Microsoft Excel, in order to use its facilities on manipulating data.

\section{RESULTS}

In order to measure the research potential in the institution, a survey was sent to the faculty staff, as a tool to collect all the requisite information. This appliance was organized in four distinct parts. The questionnaire form was created with Google Forms. Following the title of the questionnaire a brief description of the purpose of the form was given, with its objectives and any special instructions or other useful information for its correct fulfilment.

The first part is intended to fill all the information about the researcher: name, number ID, institution, academic degrees' information, scientific area, and research profiles (ORCID, Researcher ID, Scopus Author ID, and Authenticus ID). Some of the questions are textual, other of multiple choice. For some answers another link is presented for further information. For instance, by choosing the PhD option a new hyperlink appears to fill the information about the PhD.

In the second part we gathered information about scientific production, with multiple choices: indexed papers, books, book chapters and indexed conference papers, with the respective indexes (DOI, URL, ISBN, WoS, Scopus), and also other scientific indicators such as performances and exhibitions in the research scope.

The third part includes several information about research, such as funded research projects and the level of participation of the researcher (project main researcher, member of the team), prizes, affiliation to centres and research units, scientific area and sub-area, and supervision of $\mathrm{PhD}$ thesis.

Finally, the fourth part contains an open textual answer for suggestions.

The questionnaire was designed with multiple hyperlinks, in order to reduce the amount of time spent in its fulfilment and minimize the errors. This option also made possible to automatically organize data in several tables, making it easier to import them from a Database Management System (DBMS) such as Microsoft Access or MySQL. 


\section{DISCUSSION AND CONCLUSION}

The questionnaire was constructed from scratch, taking into account the usual international quality indicators. We had to maintain a balance between building a user-friendly tool and assuring homogeneous and comparable results. Aiming that goal, we chose to use multiple options with all the information previously defined, whenever it was pertinent: for instance, for the academic qualifications we used CNAEF definitions (Portuguese classification of education areas), and for the scientific research area we used FCT definitions (Portuguese national funding agency for science, research and technology).

Another advantage is the fact that responders avoid parts of the questionnaire that are not intended for them. For instance, if they chose PhD option they will be taken to a new page where they will fulfil the information, otherwise they will proceed to the following question.

The simplicity of the tool applies not only to the final users but also to the administrators that manage the questionnaire. With a very easy design and a very complete set of tools, it is very simple to create and format a questionnaire. Furthermore, answers are automatically saved to Google Spreadsheet documents, which may be managed to obtain statistical data or exported to other formats, such as CSV, and be imported by other DBMS.

Finally, Google Forms is free software, which is also an advantage. Unlike other free tools, it has all the capabilities without the difference between trial and paid versions, and it fulfils all our demands.

For future work, we want to automatically fill all previous information for each person before sending the questionnaire, so that they only need to update it. We would also like to have some of the information automatically filled by external sources, such as ORCID or Authenticus.

Another feature that we will work on is the creation of a public profile Web page with all this information, which is a way of promoting transparency and motivating faculty staff to produce more. This information must also be exported to the university information system and to the Quality Assurance System.

In sum, these results provide relevant key performance indicators, that could help managers and researchers gauge the effectiveness of various functions and processes important to achieving organizational goals. If scientific research is a strategic issue to higher education institutions, this kind of KPIs could be used to help academic managers to assess whether they or their faculty/research staff are on or off target towards those goals. On the other hand, quality assurance and assessment play many important roles in the research community. They inform crucial decisions on the funding of projects, teams and whole institutions, on how research is conducted, on recruitment and promotion, and on what is published or disseminated, and on what researchers and others choose to read. They form a crucial underpinning for trust in the work of the research community.

\section{ACKNOWLEDGEMENTS}

Authors team thanks to all faculty staff members which not only answered the questionnaire, but also shared their perceptions, suggestions and critics to the best development of the tool construction. To all, our special thanks. 


\section{REFERENCES}

[1] Dias D, Amaral A. Assessment of Higher Education Learning Outcomes (AHELO). In: Quality Assurance in Higher Education [Internet]. Palgrave Macmillan; 2014. Available from: http://www.palgraveconnect.com/doifinder/10.1057/9781137374639.0010

[2] Veiga, A., Rosa, M. J., Dias, D., Amaral, A., Why is it difficult to grasp the impacts of the Portuguese quality assurance system? European Journal of Education, 48(3), 454-470; 2013. http://doi.org/10.1111/ejed.12040

[3] Clancy, P, David D. (eds.) The Research Mission of the University: Policy Reforms and Institutional Responses. Rotterdam: Sense Publishers; 2009.

[4] Clark BR. Creating entrepreneurial universities: Organizational pathways of transformation. Oxford: Pergamon Press; 1998.

[5] Cohen WM, Nelson RR, Walsh JP. Links and Impacts : The Influence of Public Research on Industrial R \& D. Manage Sci. 2002;48(1):1-23.

[6] Abramo G, D'Angelo CA. Evaluating university research: Same performance indicator, different rankings. J Informetr. 2015;9(3):514-25.

[7] Hohendahl PU. Humboldt Revisited: Liberal Education, University Reform, and the Opposition to the Neoliberal University [Internet]. Vol. 38, New German Critique. 2011. p. 159-96. Available from: http://ngc.dukejournals.org/cgi/doi/10.1215/0094033X-1221812

[8] Caraça JMG, Conceição R, Heitor M V. Uma perspectiva sobre a miss??o das universidades. Vol. 31, Analise Social. 1996. p. 1201-33.

[9] Pereira EM de A. A Universidade da modernidade nos tempos atuais. Avaliação Rev da Avaliação da Educ Super [Internet]. 2009 Mar;14(1997):29-52. Available from: http://www.scielo.br/scielo.php?script=sci arttext\&pid=S1414$40772009000100003 \&$ Ing=pt\&nrm=iso\&tlng=pt

[10] Adham KA, Kasimin H, Mat Isa R, Othman F, Ahmad F. Developing a Framework for a Viable Research University. Syst Pract Action Res. 2015;28(5):503-25.

[11] Research Information Network (RIN). Reinventing research? Information practices in the humanities. London: RIN; 2011. http://www.rin.ac.uk/our-work/using-and-accessinginformationresources/information-use-case-studies-humanities

[12] Aaker D., Kumar V., Day GS. Marketing Research. 2nd ed. São Paulo: Atlas; 2013. 